\title{
EDITORIAL \\ Have We Forgotten About the Needs of Children?
}

\author{
David Markenson, MD, MBA
}

$\mathrm{I}$ $\mathrm{n}$ the wake of the September 11th bombing; natural disasters such as hurricanes Katrina, Rita, and Sandy; and public health emergencies such as H1N1 epidemics, the emphasis on disaster preparedness has increased. However, after each of these episodes has been a realization that the needs of children were not fully addressed. In spite of repeated efforts to acknowledge their importance and to address them adequately, the progress in meeting the needs of children has lagged far behind those to improve preparedness in general.

Initially, this gap in preparedness had been attributed to the lack of knowledge of how to address these needs. Yet after more than 10 years considerable study has focused on how to improve emergency preparedness for children, including the reports of the National Commission on Children and Disasters. As stated in the 2010 report, "We do not suggest that our Nation is completely unprepared for assisting children affected by disaster. Existing capabilities can and should be built on to integrate children into preparedness, planning, response, and recovery. In our final analysis, meeting the needs of children in disaster planning and management is a national responsibility lacking not only sufficient funding, but also a pervasive concern, a sustained will to act, and a unifying force." In spite of having a direction to follow, we have not proceeded to improve their care. One must now ask if we have forgotten about the needs of children in our disaster planning.

\section{PERCEIVED PROBLEMS IN IMPLEMENTATION}

Programs and practices for managing disasters are fragmented and unaccountable to the needs of children; instead, they have been designed primarily to help able-bodied adults. Children are categorized as an at-risk, special needs, or vulnerable population, a well-intended consideration that inadvertently creates their neglect, in that they receive less rather than more attention in disaster planning and management. This designation often excludes children in planning for disaster preparedness, as they are considered not a part of the general population but a special population. This distinction then leads to their separation from the overall plan, in that special populations are considered only as time and resources permit, rather than being incorporated as an integral part of all communities. Consequently, population planning, which is a hallmark of emergency management, must always address the needs of children from the beginning.

A lack of focus on children, while not excusable, is understandable. Traditional planning for terrorism and acts of violence has been based on combat research, and studies conducted by the military have focused on adult victims. In addition, disaster planning for natural disasters often has a significant focus on the care of traumatic injuries, an area in which research and approaches for children lag behind both the knowledge and capacity for adult care. Moreover, planning for children entails a variety of factors. Unlike planning for adults, one must address more than one age range and more geographic locations than just home or work. Instead, planning has to consider children who are at home, in school or daycare, or in transit, as well as children who may become separated from their families. In addition, planning must address children of different developmental and physiological stages (ie, from neonates, infants, and toddlers to adolescents) and those with special health care needs, especially if their survival depends on advanced technological systems.

Children are uniquely vulnerable in disasters and terrorist events because of anatomic, physiological, and clinical factors, as well as developmental and psychological concerns. While children may respond more rapidly to therapeutic intervention, they also are more susceptible to various agents and conditions, and their health is increasingly likely to deteriorate if not carefully monitored and treated. Children represent nearly $25 \%$ of our population. On any given weekday, 67 million children may be in school or child care and most vulnerable because they are away from their families. While emergency medical services (EMS) and emergency department preparedness for children have improved due to efforts such as specific EMS programs for children, only 25\% of EMS agencies and $6 \%$ of hospital emergency departments have supplies and equipment to treat children. Even the Strategic National Stockpile, which is intended to provide the public with medicine and medical supplies in the event of a public health emergency, is, in spite of some improvements, woefully understocked with medical countermeasures for children. 


\section{ENHANCING PREPAREDNESS}

To advance the needs of children, several key areas need to be addressed. These include improved preparedness at the federal, state, regional, and local levels; performance indicators to gauge success and target improvement; and research to advance the field and further improve our efforts.

The pathway to enhanced emergency preparedness for children has been articulated in several excellent reports, from the most recent, the National Commission on Children and Disasters: 2010 Report to the President and Congress, ${ }^{1}$ through reports issued by the National Center for Disaster Preparedness ${ }^{2,3}$ and the Center for Disaster Medicine ${ }^{4}$ to those from the National Advisory Committee on Children and Terrorism in 2003, after the Bioterrorism Preparedness Act of 2001 was passed. Further delineation of recommendations therefore is not needed. What is required to assure children are not forgotten is to implement the recommendations of each of these analyses, with a special focus on those from the National Commission on Children and Disasters.

Probably the most essential action that needs to be taken comes from the National Commission's request, which asks for "the President to develop and present to Congress a National Strategy on Children and Disasters. Under the imprimatur of the President, the strategy would sound an unequivocal call to action for Federal, State, territorial, tribal, and local levels of government; private sector industry; nongovernmental agencies; faith-based partners; academia; communities; families; and individuals to engage one another around a cohesive set of meaningful national goals and priorities to remedy the years of benign neglect of children." In addition it is essential that the National Advisory Committee on Children and Disasters as defined in Section 103 of the Pandemic and All-Hazards Preparedness Re authorization Act of 2013 be enacted and provided sufficient funding and staff support to carry out its essential mission. Furthermore the recommendations of the this Advisory Council should be implemented in as rapid a pace as possible with an annual report to the committee, congress, the president and made public except for classified information from each cabinet secretary and federal agency names in the recommendations documenting their progress in implementing the recommendations.

A clear deficiency in the current evaluation of disaster response is the lack of objective, quantifiable measures of performance. This lack frequently leads to assessments that are highly subjective and dependent on the evaluator, do not provide planners with targets to achieve, and do not allow for measures that show improved preparedness. Other than the occasional case report of events experienced and a recording of the victims affected and treated, little has been done to establish a rigorous performance assessment of the response to an actual disaster. Therefore, objective data on the present performance level of emergency preparedness are not available, making it difficult to direct efforts to improve. This critical deficiency may be especially problematic for pediatric care. It is also important to develop performance measures that not only address the unique needs of children but also are universally accepted to allow for benchmarking and comparisons.

To develop these measures, existing validated approaches to developing performance measures must be used by focusing on the domains of volume, structure, process, and outcome. These foundational measures can then be supplemented with the use of surrogate measures to overcome the problem caused by the infrequency of disaster events and the benefit of adopting existing validated health care performance measures. In the short term, out of necessity, we will need to use existing volume and structural measures that are currently used in emergency preparedness and adapt them to contain pediatricspecific components. We then will need to develop unique and specific pediatric emergency preparedness performance measures based on empiric quantitative measures, which in the long term will provide the data to develop validated pediatric emergency preparedness performance measures that are based on collected data. Ultimately, these pediatric-specific measures must be put into practice to assess current levels of performance, guide resource allocation, and target improvement efforts.

Finally, we must prepare not only for today but also assure that our future planning for children is based on evidence and that the field of pediatric emergency preparedness is constantly advancing. These goals can be assured through active research and promulgation of these research findings combined with the distribution of best practices and lessons from the field. To facilitate this approach, federal funding for emergency preparedness must be increased and require support for research into the needs of children. Also, preplanning must occur to allow for the rapid deployment of research teams, combined with mechanisms for institutional review board approval, to allow research to be conducted after actual events. In this way, crucial data can be collected on the effects of disasters, terrorism, and public health emergencies on children and their needs in these situations. As these events are both rare and episodic, we cannot afford to miss even one opportunity to collect vital data that can advance the field of pediatric preparedness and improve the care of children. In addition, those conducting the research and those who develop best practices and lessons from the field must then make the effort to publish this information.

The key message that must be carried to researchers, planners, regulators, legislators, and all who either plan for or conduct planning for disasters, terrorism, and public health emergencies is that children are our future and we must not forget them in emergency preparedness.

\section{About the Author}

Sky Ridge Medical Center, Denver, Colorado; and Center for Disaster Medicine, New York Medical College, School of Public Health, New York, New York. 


\section{REFERENCES}

1. National Commission on Children and Disasters. 2010 Report to the President and Congress. Rockville, MD: Agency for Healthcare Research and Quality; October 2010; AHRQ publication No. 10-M037. http:// www.ahrq.gov/prep/nccdreport/.

2. Markenson D, Redlener I. Pediatric Preparedness for Disaster and Terrorism: A National Consensus Conference. New York, New York: National Center for Disaster Preparedness, Columbia University School of Public Health; 2007.

3. Emergency Preparedness for Children, Center for Disaster Medicine, New York Medical College, NY, New York. 2008 and updated 2010.

4. Pediatric Emergency Preparedness, National Guidelines. 2010 and 2012. Center for Disaster Medicine, New York Medical College, Valhalla, New York. 